\title{
Detection of lung adenocarcinoma with ROSI rearrangement by IHC, FISH, and RT-PCR and analysis of its clinicopathologic features
}

This article was published in the following Dove Press journal:

OncoTargets and Therapy

3I December 2015

Number of times this article has been viewed

\author{
Bing $\mathrm{Cao}^{1-3, *}$ \\ Ping Wei ${ }^{1-3, *}$ \\ Zebing $\mathrm{Liu}^{4}$ \\ Rui $\mathrm{Bi}^{\mathrm{I}-3}$ \\ Yongming $\mathrm{Lu}^{\mathrm{I}-3}$ \\ Ling Zhang ${ }^{1-3}$ \\ Jing Zhang ${ }^{1-3}$ \\ Yusi Yang ${ }^{1-3}$ \\ Chen Shen ${ }^{1-3}$ \\ Xiang $\mathrm{Du}^{1-3}$ \\ Xiaoyan Zhou ${ }^{1-3}$ \\ 'Department of Pathology, Fudan \\ University Shanghai Cancer Center, \\ Shanghai, People's Republic of \\ China; ${ }^{2}$ Department of Oncology, \\ Shanghai Medical College, ${ }^{3}$ Institute \\ of Pathology, Fudan University, \\ Shanghai, People's Republic of China; \\ ${ }^{4}$ Department of Pathology, Renji \\ Hospital, School of Medicine, Shanghai \\ Jiaotong University, Shanghai, People's \\ Republic of China \\ *These authors contributed equally \\ to this work
}

Objective: To detect ROS1 rearrangement using three different assays, including immunohistochemistry (IHC), fluorescence in situ hybridization (FISH), and reverse transcription polymerase chain reaction (RT-PCR), and to analyze the clinicopathologic features of ROS1 rearrangement in patients with lung adenocarcinoma.

Methods: One hundred eighty-three consecutive patients with lung adenocarcinoma with operation and follow-up data were analyzed for ROS1 rearrangement by IHC, FISH, and RTPCR. PCR products of the RT-PCR-positive samples were sequenced for confirmation of the specific fusion partners.

Results: Three of the $183(1.64 \%)$ cases were identified to be positive for ROS1 rearrangement through all three methods. The fusion patterns were CD74 e6-ROS1 e32, CD74 e6-ROS1 e34, and TPM3 e8-ROS1 e35, respectively. FISH-positive cases showed two types of signals, single 3 ' signals (green) and split red and green signals. Using FISH as a standard method, the sensitivity and specificity of ROS1 IHC with $1+$ staining or more were $100 \%$ and $96.67 \%$, respectively. The sensitivity and specificity of RT-PCR were both $100 \%$. Univariate analysis identified female sex $(P=0.044)$, Stage I disease $(P<0.001)$, and ROS1-negative status $(P=0.022)$ to be significantly associated with longer overall survival.

Conclusion: IHC, FISH, and RT-PCR are all effective methods for the detection of ROS1 rearrangement. IHC would be a useful screening method in routine pathologic laboratories. RT-PCR can detect exact fusion patterns. ROS1 rearrangement may be a worse prognostic factor. The exact correlation of ROS1 rearrangement with prognosis and whether different fusion types are correlated with different responses to targeted therapy need to be further investigated.

Keywords: ROS1, lung adenocarcinoma, rearrangement, IHC, FISH, RT-PCR

\section{Introduction}

Lung adenocarcinoma is the most common histological subtype of lung cancer, which is the leading cause of cancer-related deaths worldwide. ${ }^{1,2}$ There is increasing evidence that lung adenocarcinoma could be divided into different molecular subgroups based on the identification of oncogenic drivers, such as EGFR, ALK, ROS1, RET, and MET, with unique clinicopathologic characteristics and the potential for targeted therapies. ${ }^{3}$

ROS1 is a receptor tyrosine kinase that encodes a transmembrane protein with evolutionary relationships to ALK. ${ }^{4} \mathrm{ROS} 1$ fusion was originally identified in the human glioblastoma cell line U118MG in $1987 . .^{5}$ Recently, ROS1 fusions have been discovered in several other tumors, including cholangiocarcinoma, ${ }^{6}$ non-small-cell lung cancer (NSCLC), ${ }^{7-12}$ ovarian cancer, ${ }^{13}$ gastric carcinoma, ${ }^{14}$ and colorectal cancer. ${ }^{15}$ ROS1 fusion in NSCLC was initially identified by Rikova et $\mathrm{al}^{7}$ in 2007 using a phosphoproteomic screen, and ROS1 fusion was shown to participate in the formation of lung
Correspondence: Xiaoyan Zhou Department of Pathology, Fudan University Shanghai Cancer Center, 270 Dongan Road, Shanghai 200032 . People's Republic of China Tel +862164175590 ext 8330 Fax +86 21 64170067 Emailxyzhoul00@163.com (c) (1) (-) $2016 \mathrm{Cao}$ et al. This work is published and licensed by Dove Medical Press Limited. The full terms of this license are available at https://www.dovepress.com/terms.php BY NC and incorporate the Creative Commons Attribution - Non Commercial (unported, v3.0) License (http://creativecommons.org/licenses//by-nc/3.0/). By accessing the work you for commercial use of this work, please see paragraphs 4.2 and 5 of our Terms (https://www.dovepress.com/terms.php). 
adenocarcinoma. Bergethon et $\mathrm{al}^{8}$ found that the features most commonly associated with ROS1-fusion NSCLC were young age, never-smoking history, adenocarcinoma, and higher tumor grade. Further studies confirmed adenocarcinoma as the predominant histological type in ROS1-fusion NSCLC. ${ }^{9,10}$ In addition, ROS1 fusion generally does not overlap with other known oncogenic drivers, such as EGFR mutation and ALK rearrangement. ${ }^{7,8,10}$

Preclinical and clinical data have shown that ROS1 fusion cases with NSCLC are sensitive to the ALK inhibitor crizotinib. ${ }^{8}$ Crizotinib is a multitargeted kinase inhibitor, and it has been approved by the US Food and Drug Administration for the treatment of patients with $A L K$ rearrangementpositive NSCLC. Recently, updated efficacy and safety data for an ongoing Phase I crizotinib study (NCT00585195) indicated that crizotinib was an effective therapy for advanced ROS1-fusion NSCLC. ${ }^{16}$ And in the National Comprehensive Cancer Network guidelines for NSCLC, crizotinib is listed as an available targeted agent for ROS1 rearrangements.

In general, ROS1 fusion occurs infrequently in lung adenocarcinoma. However, given the morbidity of lung cancer, ROS1-fusion-positive patients account for a significant number. Therefore, detection of the molecular alteration rapidly as well as accurately and understanding the tumor's clinicopathologic features are very important issues in the current clinical setting for the precise therapy of lung adenocarcinoma. In this study, we detected 183 patients with lung adenocarcinoma at our institute to identify ROS1 fusion-positive cases from DNA, RNA, and protein levels by fluorescence in situ hybridization (FISH), reverse transcription polymerase chain reaction (RT-PCR), and immunohistochemistry (IHC), respectively, assessed their values in the clinical setting, and analyzed the clinicopathologic features.

\section{Materials and methods \\ Patients and tumor samples}

This project was conducted using data and formalin-fixed paraffin-embedded (FFPE) tissue samples from Fudan University Shanghai Cancer Centre between 2007 and 2011. Patients who underwent operations and had pathologically confirmed lung adenocarcinoma and follow-up data were included. Patients treated with preoperative therapy were excluded. All clinical information was gathered by review of medical records, including age at diagnosis, sex, pathological tumor-node-metastasis (TNM) stage, and smoking history. Patients having a lifetime smoking dose of $<100$ cigarettes were defined as never smokers. Pathological diagnosis and histologic subtypes of lung adenocarcinoma were made according to the 2015 World Health Organization classification. ${ }^{17}$ The TNM stage was classified according to the 2009 International Association for the Study of Lung Cancer staging. ${ }^{18}$ This study was approved by the Fudan University Shanghai Cancer Centre Institutional Review Board, and conducted in accordance with the Declaration of Helsinki. Written informed consent was obtained from the patients.

\section{$\mathrm{IHC}$ and FISH on tissue array}

Tissue microarrays (TMAs) containing 183 cases were built using $0.6 \mathrm{~mm}$ cores. Each tumor was sampled from two different representative sites. TMA sections were baked and deparaffinized, followed by antigen retrieval with the use of sodium citrate $(\mathrm{pH}=6.0)$. Sections were then subjected to incubation with ROS1 (D4D6) rabbit monoclonal antibody (1:200; Cell Signaling Technology, Danvers, MA, USA) overnight at $4{ }^{\circ} \mathrm{C}$. Detection was conducted with EnVision+ (Dako Denmark A/S, Glostrup, Denmark). The interpretation of IHC results was conducted as described previously: ${ }^{19} 0$, no staining or nuclear expression only; $1+$, faint cytoplasmic staining not exceeding background in any cells; $2+$, cytoplasmic staining exceeding background in $0 \%-50 \%$ of tumor cells; and 3+, cytoplasmic staining exceeding background in $>50 \%$ of tumor cells. FISH assays were carried out utilizing a 6q22 ROS1(Tel) Spectrum Orange Probe for research use only (Abbott Molecular Inc, Des Plaines, IL, USA) on $4 \mu \mathrm{m}$ thick FFPE slides. Red probes are hybridized to the $5^{\prime}$ region of ROS1, and green probes to the $3^{\prime}$ region containing the tyrosine kinase domain. It was considered to be split when red and green signals of the ROS1 break-apart probe were physically separated by $\geq 1$ signal diameter. Hybridized slides were stained with 4',6-diamino-2-phenylindole and examined with a BX51 fluorescence microscope (Olympus, Tokyo, Japan). Samples were defined to be positive if $>15 \%$ of tumor cells presented split signals or single $3^{\prime}$ signals. ${ }^{9}$

\section{RNA extraction, RT-PCR, and sequencing}

Extraction of total RNA from FFPE tissue sections was accomplished using the RecoverAll ${ }^{\mathrm{TM}}$ Total Nucleic Acid Isolation Kit for FFPE (Thermo Fisher Scientific, Waltham, MA, USA) following the appropriate protocols. RNA was then reverse transcribed into cDNA, using the ROS1 fusion gene detection kit (AmoyDx, Fujian, People's Republic of China). The reverse transcription conditions were as follows: $42^{\circ} \mathrm{C}, 60$ minutes; $95^{\circ} \mathrm{C}, 5$ minutes. Then, PCR was conducted to screen for ROS1 gene fusions on an ABI 7500 system (Applied Biosystems, Foster City, CA, USA) with the 
Table I The types of ROSI gene fusion involved in this study

\begin{tabular}{lll}
\hline $\begin{array}{l}\text { Fusion } \\
\text { number }\end{array}$ & $\begin{array}{l}\text { Fusion partners } \\
\text { for ROSI, exon }\end{array}$ & ROSI exon \\
\hline 1 & SLC34A2, e4 & 32 \\
2 & SLC34A2, el4del & \\
3 & CD74, e6 & \\
4 & SDC4, e2 & \\
5 & SDC4, e4 & 34 \\
6 & SLC34A2, e4 & \\
7 & SLC34A2, el4del & \\
8 & CD74, e6 & \\
9 & SDC4, e4 & \\
10 & EZR, el0 & 35 \\
11 & TPM3, e8 & \\
12 & LRIG3, el6 & 36 \\
13 & GOPC, e8 & \\
14 & GOPC, e4 & \\
\hline
\end{tabular}

ROS1 fusion gene detection kit (AmoyDx). The ROS1 fusion types involved in our study are listed in Table 1 . The PCR conditions were as follows: $95^{\circ} \mathrm{C}$ for 5 minutes, 1 cycle; $95^{\circ} \mathrm{C}$ for 25 seconds, $64^{\circ} \mathrm{C}$ for 20 seconds, $72^{\circ} \mathrm{C}$ for 20 seconds, 15 cycles; and $93^{\circ} \mathrm{C}$ for 25 seconds, $60^{\circ} \mathrm{C}$ for 35 seconds, $72^{\circ} \mathrm{C}$ for 20 seconds, 31 cycles. Finally, PCR products of the RT-PCR-positive samples were directly sequenced for verification and the specific fusion partners.

\section{Statistical analysis}

Categorical variables were compared using the $\chi^{2}$ test and Fisher's exact test when appropriate. Relapse-free survival (RFS) was measured from the time of resection to the time of the first disease progression or relapse or death resulting from any cause. Overall survival (OS) was calculated from the time of resection to the time of death from any cause or the time of the last follow-up. Estimates of RFS and OS were made by the Kaplan-Meier method, and differences between curves were analyzed using the log-rank test. Statistical analysis was conducted using the SPSS 16.0 software package (SPSS, Chicago, IL, USA).

\section{Results}

A total of 183 consecutive patients with primary lung adenocarcinoma with surgical operation and follow-up data were enrolled. All patients were of Chinese origin. These patients were followed up from the date of resection to the time of death or the time of the last follow-up (December 2013). The median follow-up time was 40 months. A summary of the main clinical features in all patients is listed in Table 2. The median age at diagnosis was 58 years. Of these, 92 patients were male and 91 were female. One hundred and six patients
Table 2 Clinical characteristics of patients with lung adenocarcinoma

\begin{tabular}{|c|c|c|c|}
\hline \multirow[t]{2}{*}{ Characteristic } & \multirow[t]{2}{*}{ All $(n=183)$} & \multicolumn{2}{|c|}{ ROSI fusion } \\
\hline & & $\begin{array}{l}\text { Positive } \\
(n=3)\end{array}$ & $\begin{array}{l}\text { Negative } \\
(n=180)\end{array}$ \\
\hline \multicolumn{4}{|l|}{ Age (years) } \\
\hline Median (range) & $58(33-75)$ & $49(45-55)$ & $58(33-75)$ \\
\hline$<60$ & 110 (60.11\%) & $3(100 \%)$ & 107 (59.44\%) \\
\hline$\geq 60$ & 73 (39.89\%) & $0(0 \%)$ & 73 (40.56\%) \\
\hline \multicolumn{4}{|l|}{ Sex } \\
\hline Male & 92 (50.27\%) & $2(66.67 \%)$ & $90(50 \%)$ \\
\hline Female & 91 (49.73\%) & I (33.33\%) & $90(50 \%)$ \\
\hline \multicolumn{4}{|l|}{ Smoking history } \\
\hline Never & 106 (57.92\%) & $2(66.67 \%)$ & 104 (57.78\%) \\
\hline Ever & 77 (42.08\%) & I (33.33\%) & 76 (42.22\%) \\
\hline \multicolumn{4}{|l|}{ Stage } \\
\hline 1 & 85 (46.45\%) & $0(0 \%)$ & 85 (47.22\%) \\
\hline ॥ & $33(18.03 \%)$ & $0(0 \%)$ & 33 (I8.33\%) \\
\hline III & 65 (35.52\%) & $3(100 \%)$ & 62 (34.44\%) \\
\hline IV & $0(0 \%)$ & $0(0 \%)$ & $0(0 \%)$ \\
\hline
\end{tabular}

were never smokers. The number of patients with Stages I-IV disease were 85 (46.45\%), 33 (18.03\%), 65 (35.52\%), and $0(0 \%)$, respectively. Eleven patients with Stage IB disease having high-risk factors and all patients with Stages II and III disease were treated with adjuvant chemotherapy after operation. Sixty-one relapsed/metastatic patients received chemotherapy and/or radiation therapy according to patients' conditions and guidelines. Twenty-five of the 61 patients with $E G F R$ mutations received gefitinib or erlotinib off protocol. Other patients including $14 E G F R$ mutation-negative patients and 22 patients with unknown $E G F R$ status were not treated with targeted therapy. None of the patients, including the three ROS1-positive cases, received crizotinib.

\section{Comparison of ROSI IHC, FISH, and RT-PCR}

Nine of 183 cases showed some degree of ROS1 protein expression by IHC analysis, and 174 cases showed no ROS1 expression. Four cases showed 3+, three cases showed 2+, and two cases showed 1+(Figure 1). Among the 183 cases, three cases were both FISH- and RT-PCR-positive for ROSI rearrangement, and the other 180 cases were both FISH- and RT-PCR-negative (Table 3). Of the three FISH- and RTPCR-positive cases, two exhibited 3+ IHC staining, and one exhibited $2+$ staining. Using FISH as a standard method for ROS1 rearrangement, the sensitivity and specificity of RT-PCR were $100 \%$ and $100 \%$, respectively; of IHC with $1+$ staining or more, these values were $100 \%$ and $96.67 \%$, respectively. If IHC with $2+$ and $3+$ staining was considered positive, the sensitivity and specificity of ROS1 IHC were 

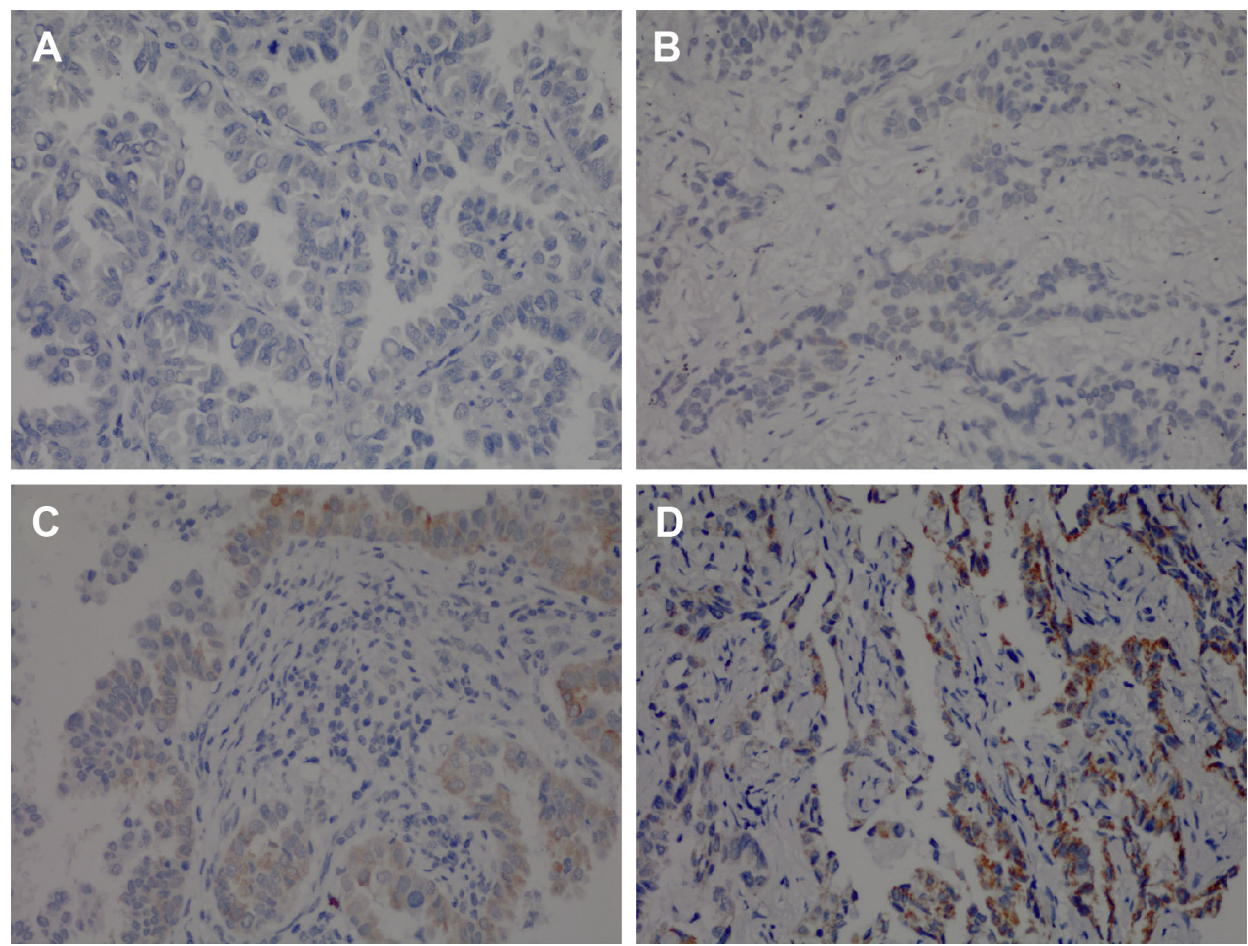

Figure I Detection of ROSI fusion in lung adenocarcinoma patients by IHC.

Notes: (A) Score 0 showing no staining. (B) Score I+ showing faint cytoplasmic staining. (C) Score $2+$ showing $<50 \%$ of tumor cells with moderate staining. (D) Score $3+$ showing $>50 \%$ of tumor cells with strong staining.

Abbreviation: IHC, immunohistochemistry.

$100 \%$ and $97.78 \%$, respectively. Finally, we identified these three cases to be positive for ROS1 rearrangement for further analysis.

\section{ROSI gene fusions}

Three out of 183 (1.64\%) patients were positive for ROS1 fusions, as observed through IHC, FISH, and RT-PCR. For FISH-positive cases, one case showed single 3' signals (green) and two cases showed split red and green signals. For RT-PCR-positive cases, three different fusion patterns

Table 3 Comparison of IHC, FISH, and RT-PCR detection for ROSI rearrangement

\begin{tabular}{llll}
\hline Case number & IHC & FISH & RT-PCR \\
\hline 1 & $3+$ & Positive & Positive \\
2 & $3+$ & Positive & Positive \\
3 & $3+$ & Negative & Negative \\
4 & $3+$ & Negative & Negative \\
5 & $2+$ & Positive & Positive \\
6 & $2+$ & Negative & Negative \\
7 & $2+$ & Negative & Negative \\
8 & $1+$ & Negative & Negative \\
9 & $1+$ & Negative & Negative \\
$10-183$ & 0 & Negative & Negative \\
\hline
\end{tabular}

Abbreviations: IHC, immunohistochemistry; FISH, fluorescence in situ hybridization; RT-PCR, reverse transcription polymerase chain reaction. were identified: CD74 e6-ROS1 e32, CD74 e6-ROS1 e34, and TPM3 e8-ROS1 e35, respectively (Figure 2).

\section{Analysis of clinicopathologic features}

The clinical features and fusion types of all three ROS1positive patients are listed in Table 4. All three ROS1-positive patients were younger than 60 years, had EGFR wild type, and had Stage III disease. The pathological type was papillary predominant, solid partial; acinar predominant, solid partial; and invasive mucinous adenocarcinoma, respectively. Two of the three showed relapse or had died within 18 months.

Survival analyses were carried out in 183 patients. Fortysix (25.14\%) death events occurred during the follow-up period, including 44 (24.44\%) in ROS1-negative patients and two (66.67\%) in ROS1-positive patients. The median OS for ROS1-negative and ROS1-positive patients were 40 and 18 months, respectively. ROSl-negative patients had a significantly longer OS than ROSI-positive patients, with a $P$-value of 0.022 . Univariate analysis (Table 5) identified female sex $(P=0.044)$, Stage I disease $(P<0.001)$, and ROS1negative status $(P=0.022)$ to be significantly associated with longer OS. For RFS, univariate analysis identified female sex $(P=0.004)$, Stage I disease $(P<0.001)$, and never smoking history $(P=0.016)$ to be significantly associated with longer 

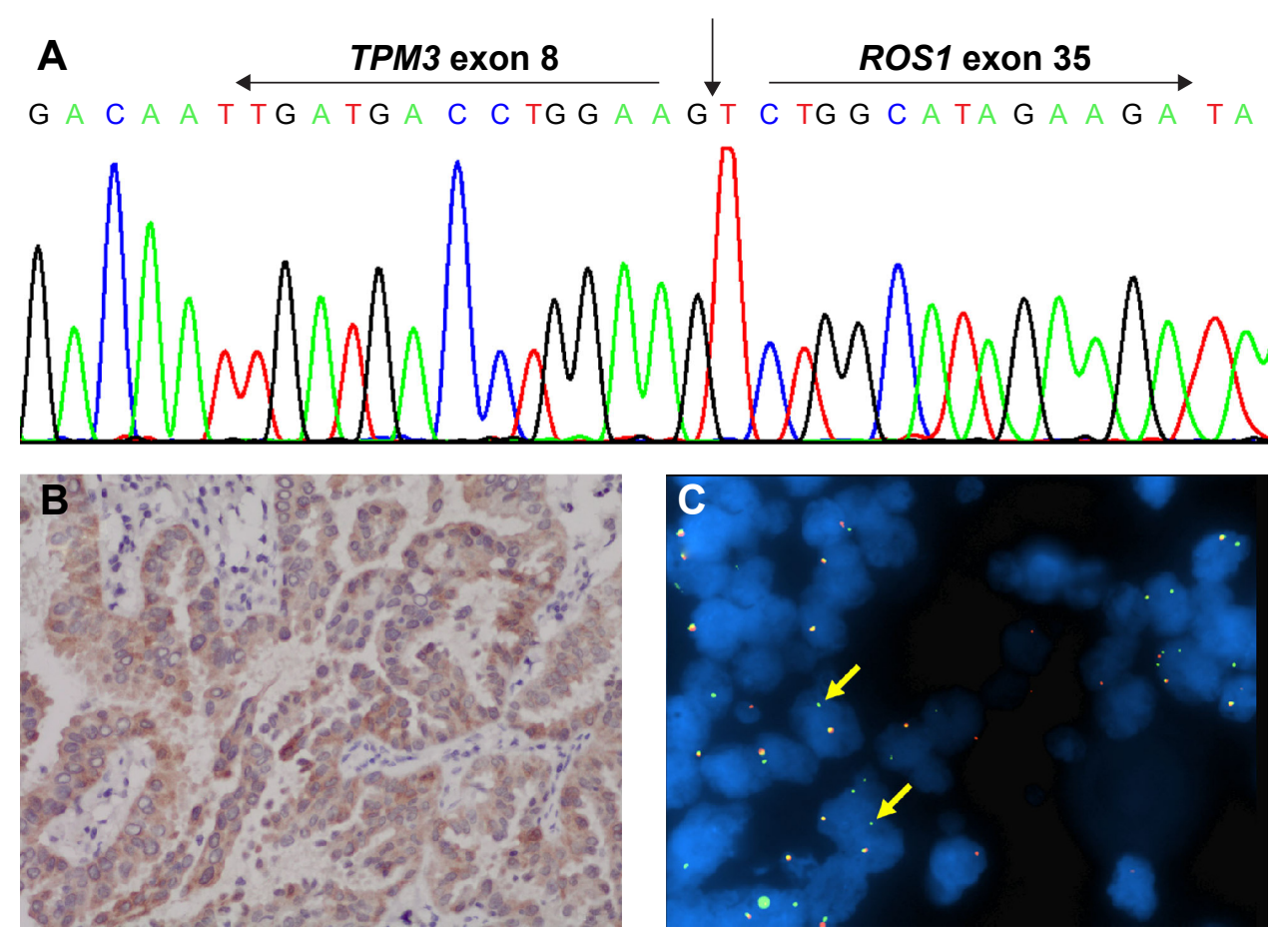

Figure 2 Representative images of ROSI sequencing, IHC and FISH results (patient number 3).

Notes: (A) Sequencing of the product from RT-PCR harboring TPM3 e8-ROSI e35 rearrangement. (B) IHC reveals cytoplasmic ROSI staining ( $\times 400)$. (C) Break-apart FISH analysis shows single green signal pattern (yellow arrows). Red probes are hybridized to the $5^{\prime}$ region of ROSI and green probes to the $3^{\prime}$ region.

Abbreviations: IHC, immunohistochemistry; FISH, fluorescence in situ hybridization; RT-PCR, reverse transcription polymerase chain reaction.

RFS. Multivariate analysis identified low-stage disease $(P<0.001)$ as being the independent prognostic factor for better OS and RFS.

\section{Discussion}

ROS1 rearrangements have been identified as oncogenes in several tumors, including glioblastoma, cholangiocarcinoma, NSCLC, ovarian cancer, gastric carcinoma, and colorectal cancer, ${ }^{5,6,8,13-15}$ suggesting that $R O S 1$ is likely to be an effective molecular target in these patients. Targeting ROS1 inhibitors have been used clinically for advanced lung adenocarcinoma, and so the detection of ROSI rearrangements with appropriate methods to select sensitive patients is suggested. Similar to the detection of $A L K$ rearrangements, three methods, including FISH, IHC, and RT-PCR, were applied to detect ROS1 rearrangement. Each method has its own advantages and disadvantages. To date, the comparison of these three methods in the detection of ROS1 rearrangement is rare..$^{20}$ In this study, we assessed the values of three methods in the clinical setting and analyzed the clinicopathologic features of ROS1-positive patients with lung adenocarcinoma.

In this study, ROS1 rearrangements were identified in three lung adenocarcinoma patients using IHC, FISH, and RT-PCR, with a prevalence of $1.64 \%$. Two of three patients harbored the CD74-ROS1 fusion partner, and the third exhibited TPM3-ROS1. These may represent the most common fusion types of ROS1 rearrangement. ROS1-negative patients had a significantly longer OS than $R O S 1$-positive patients ( 40 vs 18 months, $P=0.022$ ), and this was consistent with the results of a study by Cai et al. ${ }^{12}$ However, there were only three ROS1-positive cases, more patients with ROS1-positive need to be collected to confirm the conclusion in the future.

The break-apart FISH assay is the only assay clinically approved by the FDA to detect $A L K$-rearranged NSCLC. However, there are advantages and disadvantages to the break-apart FISH assay. FISH could be performed even if the concrete fusion partner is not known, and it has the potential to discover all fusions for ROS1 in NSCLC and other solid tumors. In terms of the interpretation of the results, FISH is more objective than IHC. On the other hand, the FISH assay requires special equipment and a high level of professional knowledge and is more expensive than other assays. These drawbacks limit the application of FISH in all clinical institutions. The RT-PCR assay is easy to perform, highly sensitive, and relatively inexpensive. In addition, RT-PCR can identify concrete fusion partners, which can be confirmed by subsequent sequencing. Therefore, it is an important assay for the detection of ROS1 rearrangement. 


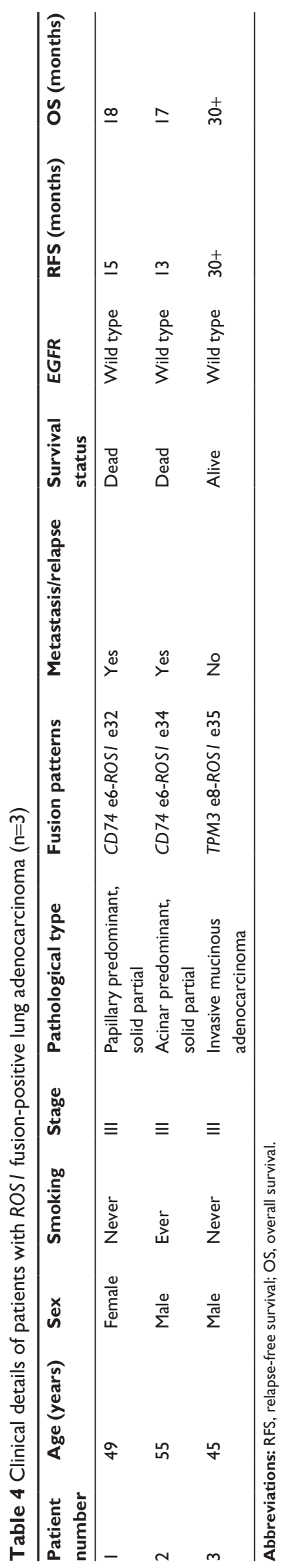

Table 5 Univariate analyses of prognostic factors in patients with lung adenocarcinoma

\begin{tabular}{lll}
\hline Variables & \multicolumn{2}{l}{ Univariate $\boldsymbol{P}$-value } \\
\cline { 2 - 3 } & RFS & OS \\
\hline Age $<60$ vs $\geq 60$ years & 0.378 & 0.555 \\
Female vs male & $\mathbf{0 . 0 0 4}$ & $\mathbf{0 . 0 4 4}$ \\
Stage I vs II-IV & $<\mathbf{0 . 0 0 I}$ & $<\mathbf{0 . 0 0 I}$ \\
Never smokers vs smokers & $\mathbf{0 . 0 1 6}$ & 0.169 \\
ROSI negative vs positive & 0.315 & $\mathbf{0 . 0 2 2}$ \\
\hline
\end{tabular}

Note: Bold entries indicate that the $P$-value is $<0.05$.

Abbreviations: RFS, relapse-free survival; OS, overall survival.

The drawbacks of RT-PCR are that RNA extraction from FFPE and larger amounts of tissues are required, and falsepositives may occur due to its sensitivity. In addition, RTPCR cannot discover new fusion partners other than known and designed partners.

Compared with FISH and RT-PCR, the IHC assay is simple, inexpensive, and conducted in all pathology laboratories. Sholl et a $1^{19}$ analyzed 53 lung adenocarcinoma cases to compare IHC using ROS1 (D4D6) antibody with ROS1 break-apart FISH. They found that ROS1 IHC was $100 \%$ sensitive and $92 \%$ specific for ROS1 rearrangements by FISH. Rogers et $\mathrm{al}^{21}$ found that the ROS1 IHC antibody (D4D6) had $33.3 \%$ sensitivity and $99.7 \%$ specificity, when analyzed by FISH in 304 lung cancer samples. In this study, we detected 183 lung adenocarcinoma patients by IHC with anti-ROS1 (D4D6) antibody, FISH with break-apart ROS1 probe, and RT-PCR with known common partner primers. The sensitivity and specificity of ROS1 IHC were $100 \%$ and $97.78 \%$, respectively, according to FISH. These results showed that IHC using the ROS1 (D4D6) antibody was highly sensitive and specific for the detection of ROS1 rearrangements in NSCLC, and IHC was a fast screening test for low incidence but clinically significant genetic translocations in tumors. In our study, six cases with IHC positivity were negative for FISH and RT-PCR. The reason might be that a mechanism other than ROS1 rearrangement leads to ROS1 protein expression. Lee et $\mathrm{al}^{22}$ found that promoter hypomethylation was able to activate ROS1 in NSCLC, suggesting epigenetic changes were relevant to ROS1 expression. ROS1 copy number gain may be another mechanism of ROS1 expression. Lee et $\mathrm{al}^{22}$ identified one-lung adenocarcinoma case with ROS1 copy number gain and strong ROS1 expression in primary and corresponding metastatic tumors. However, Jin et $a^{23}$ reported that there was no statistically significant correlation between ROS1 copy number gain and protein overexpression in NSCLC. Further researches are needed to elucidate other mechanisms for ROS1 expression. 
In addition to FISH, RT-PCR, and IHC, with the development of next-generation sequencing (NGS) technology, NGS has been introduced to detect multiple alterations in lung cancer genes simultaneously. ${ }^{24-26}$ Drilon et a ${ }^{25}$ retested 31 patients with lung adenocarcinoma with a broad, hybrid capture-based NGS assay. These patients were previously assessed "negative" for alterations in eleven genes (including ROS1) via multiple non-NGS methods. Among the genomic alterations uncovered by NGS, CD74-ROS1 was identified in one patient. Peled et a ${ }^{27}$ described an NSCLC patient who was detected negative for $A L K$ rearrangement by FISH but had a complex $A L K$ rearrangement by NGS analysis. The patient responded to crizotinib. Therefore, NGS is a sensitive and high-throughput method to detect genes alterations including ROS1 rearrangement compared to FISH and is being increasingly used in clinical molecular testing in lung cancer.

Bergethon et $\mathrm{al}^{8}$ examined ROS1 rearrangement in a multicenter cohort of 1,073 NSCLC patients with a prevalence of $1.7 \%$ and defined this molecular subset of NSCLC in patients of younger age, those with never-smoking history, adenocarcinoma, and higher grade cancer. Yoshida et $\mathrm{al}^{28}$ identified 15 ROS1-positive patients from 799 NSCLC cases, with a prevalence of $1.9 \%$. The ROS1-positive patients were often younger nonsmoking female individuals with adenocarcinomas. Zhu et $\mathrm{al}^{29}$ performed a meta-analysis to analyze the clinicopathologic characteristics of NSCLC patients harboring ROS1 rearrangements. Pooled results showed that significantly higher rate of ROS1 rearrangement was detected in female patients, nonsmoking patients, adenocarcinoma, and patients with Stages III-IV disease. We identified three patients with ROS1 rearrangement from 183 Chinese lung adenocarcinoma patients with operation and follow-up data, with a prevalence of $1.64 \%$. The ages of the three patients were 49,55 , and 45 years, respectively, and they tended to be younger. Only one patient had ever smoked. Three patients presented with Stage III disease. The clinical features of ROS1-positive patients in our study were consistent with the studies by Bergethon et al, ${ }^{8}$ Yoshida et al, ${ }^{28}$ and Zhu et al. ${ }^{29}$ Davies et $\mathrm{al}^{9}$ found that five out of 428 (1.2\%) Caucasian patients with NSCLC were positive for ROS1 rearrangement in Italy. These suggest no significant ethnic difference in the prevalence of ROS1 rearrangement.

The tyrosine kinase domain of ROS1 has a similar homology to ALK, and crizotinib, which has been approved for the treatment of $A L K$-positive NSCLC, has been explored as a therapeutic agent. In addition to crizotinib, the use of several potent ROS1 inhibitors for therapy has been studied.
Awad et $\mathrm{al}^{30}$ reported that a patient with CD74-ROS1 fusion acquired resistance to crizotinib due to mutation of G2032R in the ROS1-kinase domain. Foretinib (GSK1363089), a multikinase inhibitor effective for MEF/VEGFR2, is a potent ROS1 inhibitor in vitro and in vivo and remains sensitive to crizotinib-resistant ROS1 kinase domain mutations. ${ }^{31}$ AP26113, an oral ALK/EGFR inhibitor, can inhibit the activity of ROS1 fusion in vitro, and an ongoing Phase I/II trial (NCT01449461) plans to recruit ROS1-positive NSCLC patients. ${ }^{32}$ PF-06463922, an ALK/ROS1 inhibitor, showed efficacy in crizotinib-resistant tumors in mouse models and is in Phase I/II trial (NCT01970865). A Phase I/II trial (NCT01712217) combining the HSP90 inhibitor AT13387 with crizotinib is recruiting $A L K$ - and $R O S 1$-positive NSCLC patients who progressed while on crizotinib.

In conclusion, IHC, FISH, and RT-PCR are all effective methods for the detection of ROS1 rearrangement, with different advantages and disadvantages. CD74 e6-ROS1 e32, CD74 e6-ROS1 e34, and TPM3 e8-ROS1 e35 may be common ROS1 fusion types. IHC would be a useful routine screening method in pathology laboratories. The fact that $1.64 \%$ of cases of lung adenocarcinoma harbored the ROS1 fusion in Chinese patients suggests no regional prevalence of ROS1 rearrangements. Patients with $R O S 1$ rearrangements were younger and had higher stage disease and shorter RFS and OS. Whether ROS1 positivity is an independent prognostic factor and whether different rearrangement types correlated with different responses to targeted therapy need to be further investigated.

\section{Acknowledgments}

This study was funded by Shanghai Key Basic Research Project (10DJ1400500) and National Natural Science Foundation of China (number 81470353).

\section{Disclosure}

The authors report no conflicts of interest in this work.

\section{References}

1. Siegel R, Naishadham D, Jemal A. Cancer statistics, 2013. CA Cancer J Clin. 2013;63(1):11-30.

2. Guo P, Huang ZL, Yu P, Li K. Trends in cancer mortality in China: an update. Ann Oncol. 2012;23(10):2755-2762.

3. Berge EM, Doebele RC. Targeted therapies in non-small cell lung cancer: emerging oncogene targets following the success of epidermal growth factor receptor. Semin Oncol. 2014;41(1):110-125.

4. Robinson DR, Wu YM, Lin SF. The protein tyrosine kinase family of the human genome. Oncogene. 2000;19(49):5548-5557.

5. Birchmeier C, Sharma S, Wigler M. Expression and rearrangement of the ROS1 gene in human glioblastoma cells. Proc Natl Acad Sci US A. 1987;84(24):9270-9274. 
6. Gu TL, Deng X, Huang F, et al. Survey of tyrosine kinase signaling reveals ROS kinase fusions in human cholangiocarcinoma. PloS One. 2011;6(1):e15640.

7. Rikova K, Guo A, Zeng Q, et al. Global survey of phosphotyrosine signaling identifies oncogenic kinases in lung cancer. Cell. 2007;131(6): 1190-1203.

8. Bergethon K, Shaw AT, Ou SH, et al. ROS1 rearrangements define a unique molecular class of lung cancers. J Clin Oncol. 2012;30(8): $863-870$.

9. Davies KD, Le AT, Theodoro MF, et al. Identifying and targeting ROS1 gene fusions in non-small cell lung cancer. Clin Cancer Res. 2012;18(17):4570-4579.

10. Rimkunas VM, Crosby KE, Li D, et al. Analysis of receptor tyrosine kinase ROS1-positive tumors in non-small cell lung cancer: identification of a FIG-ROS1 fusion. Clin Cancer Res. 2012;18(16):4449-4457.

11. Takeuchi K, Soda M, Togashi Y, et al. RET, ROS1 and ALK fusions in lung cancer. Nat Med. 2012;18(3):378-381.

12. Cai W, Li X, Su C, et al. ROS1 fusions in Chinese patients with nonsmall-cell lung cancer. Ann Oncol. 2013;24(7):1822-1827.

13. Birch AH, Arcand SL, Oros KK, et al. Chromosome 3 anomalies investigated by genome wide SNP analysis of benign, low malignant potential and low grade ovarian serous tumours. PloS One. 2011; 6(12):e28250.

14. Lee J, Lee SE, Kang SY, et al. Identification of ROS1 rearrangement in gastric adenocarcinoma. Cancer. 2013;119(9):1627-1635.

15. Aisner DL, Nguyen TT, Paskulin DD, et al. ROS1 and ALK fusions in colorectal cancer, with evidence of intratumoral heterogeneity for molecular drivers. Mol Cancer Res. 2014;12(1):111-118.

16. Ou SHI, Bang YJ, Camidge DR, et al. Efficacy and safety of crizotinib in patients with advanced ROS1-rearranged non-small cell lung cancer (NSCLC) [abstract]. J Clin Oncol. 2013;31(15 Suppl).

17. Travis WD, Brambilla E, Nicholson AG, et al. The 2015 World Health Organization classification of lung tumors: impact of genetic, clinical and radiologic advances since the 2004 classification. J Thorac Oncol. 2015;10(9):1243-1260.

18. Giroux DJ, Rami-Porta R, Chansky K, et al. The IASLC lung cancer staging project: data elements for the prospective project. J Thorac Oncol. 2009;4(6):679-683.

19. Sholl LM, Sun H, Butaney M, et al. ROS1 immunohistochemistry for detection of ROS1-rearranged lung adenocarcinomas. Am J Surg Pathol. 2013;37(9):1441-1449.

20. Shan L, Lian F, Guo L, et al. Detection of ROS1 gene rearrangement in lung adenocarcinoma: comparison of IHC, FISH and real-time RTPCR. PloS One. 2015;10(3):e0120422.
21. Rogers TM, Russell PA, Wright G, et al. Comparison of methods in the detection of ALK and ROS1 rearrangements in lung cancer. J Thorac Oncol. 2015;10(4):611-618.

22. Lee HJ, Seol HS, Kim JY, et al. ROS1 receptor tyrosine kinase, a druggable target, is frequently overexpressed in non-small cell lung carcinomas via genetic and epigenetic mechanisms. Ann Surg Oncol. 2013;20(1):200-208.

23. Jin Y, Sun PL, Kim H, et al. ROS1 gene rearrangement and copy number gain in non-small cell lung cancer. Virchows Arch. 2015;466(1): 45-52.

24. Takeda M, Sakai K, Terashima M, et al. Clinical application of amplicon-based next-generation sequencing to therapeutic decision making in lung cancer. Ann Oncol. Epub September 29, 2015.

25. Drilon A, Wang L, Arcila ME, et al. Broad, hybrid capture-based next-generation sequencing identifies actionable genomic alterations in lung adenocarcinomas otherwise negative for such alterations by other genomic testing approaches. Clin Cancer Res. 2015;21(16): 3631-3639.

26. Scheffler M, Schultheis A, Teixido C, et al. ROS1 rearrangements in lung adenocarcinoma: prognostic impact, therapeutic options and genetic variability. Oncotarget. 2015;6(12):10577-10585.

27. Peled N, Palmer G, Hirsch FR, et al. Next-generation sequencing identifies and immunohistochemistry confirms a novel crizotinib-sensitive ALK rearrangement in a patient with metastatic non-small-cell lung cancer. J Thorac Oncol. 2012;7(9):e14-e16.

28. Yoshida A, Kohno T, Tsuta K, et al. ROS1-rearranged lung cancer: a clinicopathologic and molecular study of 15 surgical cases. Am J Surg Pathol. 2013;37(4):554-562.

29. Zhu Q, Zhan P, Zhang X, Lv T, Song Y. Clinicopathologic characteristics of patients with ROS1 fusion gene in non-small cell lung cancer: a meta-analysis. Transl Lung Cancer Res. 2015;4(3):300-309.

30. Awad MM, Katayama R, McTigue M, et al. Acquired resistance to crizotinib from a mutation in CD74-ROS1. N Engl J Med. 2013; 368(25):2395-2401.

31. Davare MA, Saborowski A, Eide CA, et al. Foretinib is a potent inhibitor of oncogenic ROS1 fusion proteins. Proc Natl Acad Sci USA. 2013;110(48):19519-19524.

32. Squillace RM, Anjum R, Miller D, et al. AP26113 possesses paninhibitory activity versus crizotinib-resistant ALK mutants and oncogenic ROS1 fusions [abstract]. Cancer Res. 2013;73(8 Suppl 1).
OncoTargets and Therapy

\section{Publish your work in this journal}

OncoTargets and Therapy is an international, peer-reviewed, open access journal focusing on the pathological basis of all cancers, potential targets for therapy and treatment protocols employed to improve the management of cancer patients. The journal also focuses on the impact of management programs and new therapeutic agents and protocols on

\section{Dovepress}

patient perspectives such as quality of life, adherence and satisfaction The manuscript management system is completely online and includes a very quick and fair peer-review system, which is all easy to use. Visit http://www.dovepress.com/testimonials.php to read real quotes from published authors. 